\title{
CONFLICT - CRISIS HIERARCHY IN ENGLISH NEWS DISCOURSE: COGNITIVE RHETORICAL PERSPECTIVE
}

\author{
SERHIY I. POTAPENKo \\ Kyiv National Linguistic University, Ukraine \\ potapenkoknlu@gmail.com
}

OLENA M. SHCHERBAK

Nikolai Gogol State University at Nizhyn, Ukraine

lenadfkz2@ukr.net

\begin{abstract}
The paper argues that in English on-line news the meanings of the conflict and crisis terms serve as reference points for the construction of a confrontation hierarchy. It is based on the interaction of the relations of force, serving as primes for meaning formation, with three levels of discourse prominence meant to attract, focus and keep the addressee's attention in headings, headlines and throughout the text respectively. It is found that news stories arrange the units of conflict - crisis hierarchy according to three patterns: zoom-in, offering a detailed textual representation of confrontation with support of the argumentation sections of evidence, explanation or commentary; zoom-out, generalizing on the forces, underlying confrontation construction; multiperspectivation, aimed at a multifaceted representation of conflict - crisis hierarchy.
\end{abstract}

Keywords: crisis, conflict, confrontation, English news discourse, cognitive rhetoric

\section{Introduction}

There seem to be two opposite approaches to the understanding of the meaning of the English words conflict and crisis. Some authors do not see any difference between them which is suggested by the title of the book Language of Conflict: Discussion of Ukrainian Crisis and the preface to it (Knoblock 2020: 1). According to the book title conflict-units suit quite well to describe the Ukrainian crisis. Other authorities are adamant that conflict and crisis are different phenomena and the units naming them should be distinguished. For example, the spokeswoman for the Ukrainian Ministry of Foreign Affairs criticised the BBC for referring to the situation in the east of the country in terms of crisis insisting that it was a mere conflict. In response, the broadcaster acknowledged the existence of such a difference replacing the heading Ukraine crisis with Ukraine conflict (https://www.eurointegration.com.ua/eng/news/2018/09/7/7086613/). 
Similar discrepances occur in scholarly publications. In some paper titles, the noun conflict seems to capture the way this state of affaires in Ukraine is treated by European media, e.g. Naturalising the new cold war: The geopolitics of framing the Ukrainian conflict in four European newspapers (Ojala, Pantti 2017: 41), while the term crisis is applied to the discussion of the situation by Russian media, cf. Ukrainian crisis through the lens of Russian media: Construction of ideological discourse (Pasitselska 2017: 591) and Measuring news bias: Russia's official news agency ITAR-TASS' coverage of the Ukraine crisis (Watanabe 2017: 224). A similar difference characterises the social media where pro-Ukrainian communities interpret the conflict as a limited military action against the local rebels while pro-Russian online communities regard it as an all-out war against the Russian population of Eastern Ukraine (Makhotykh, Sydorova 2017: 359).

The analysis of the English units denoting conflict and crisis reveals their use in different constructions reflecting their semantic distinctions. The meaning of the noun conflict is associated with a limited three-dimensional space indicated by the preposition in (to be in conflict with). The conflict-constructions focus on different reasons for the formation of the denoted contentious situation: the two opposing parties (conflict between), its causes (conflict over), particular spheres (political / social / industrial conflict) or its violent character brought to the fore by an array of attributes: armed / military / violent conflict. The meaning of the English phrase in crisis represents a situation as a closed space, enveloping the referent placed inside that results in hopelessness, fear, and despair. It is due to this closed space conceptualization that the crisis is associated with many other distasteful phenomena associated with the container semantics: in poverty, in debt, in distress. Judging by the existing constructions, crises seem to be numerous and distinguished by a number of attributes: energy / oil / housing / debt / border / political crisis. Their intensity is emphasised by corresponding adjectives ( $a$ major / severe crisis) interacting with verbs describing the activities of the managers hurrying to tackle the problem: resolve / solve / defuse a crisis. Drawing on those vast resources of the English language the media seem prone to name anything out of the ordinary by the fashionable word crisis, gleefully reporting on grave situations which make others suffer. However, it is overlooked that the two media terms (conflict and crisis) occurring in headings and headlines interact with a number of less frequent words employed in the text (unrest, stand-off, war, clash etc.) indicate the existence of a conflict - crisis hierarchy which can is best exemplified by the news discourse.

Consequently, the research question concerns the causes of categorizing similar or even the same states of affairs in terms of conflict, crisis and other synonyms. The appropriate answer to this question can be obtained if we analyse news discourse that is rich in the units denoting confrontation.

\section{Theoretical Background}

The primary level terms widespread in the English news discourse - conflict and crisis - can be studied from three perspectives: scholarly, dealing with the 
Conflict - crisis hierarchy in English news discourse: Cognitive rhetorical perspective

extralinguistic phenomena designated by these words; naïve, encoded in dictionary definitions in terms of common sense; rhetorical, mainly concerning crisis (Rzepecka 2018: 8) with conflict studies drifting away from rhetoric which is suggested by the name of the volume Conflict Prevention: From Rhetoric to Reality (Schnabel, Carment 2004: 3). However, the interpersonal perspective does not seem suitable for this study since it treats conflict as an essential outworking of communication (Bray, Rzepecka 2018: 1) with a special attention to individuals' conflict styles (Croucher 2017: 33).

The scholarly approaches turn out to be of little help for linguistic rhetorical studies since the theories investigating conflict work from divergent positions and use different vocabularies (Demmers 2012: 6) while there are no universally accepted interpretations of crisis (Coombs 2012: 19). The standard definition of conflict as any situation in which two or more parties perceive that they possess mutually incompatible goals (Demmers 2012: 4) is too vague since it fails to clarify how those non-linguistic goals can be taken into account while the interpretations of crisis are too heterogeneous: they cover a variety of phenomena ranging from control and risk manifestations (Heath 2012: 3) to anomalous dimensions and sets of unusual negative events (Coombs 2012: 18).

The naïve definitions of the units conflict and crisis registered in dictionary entries seem more uniform and acceptable for linguistic and rhetorical purposes. The meaning of the noun conflict, defined as "a state of disagreement or argument between people, groups, countries etc" (LDOCE), rests on the semantic features 'disagreement' and 'argument' referring to a confrontation between the opponents of approximately similar scale. The dictionary interpretation of the term crisis as "a time of great danger, difficulty or confusion, when problems must be solved or important decisions must be made" (OALD) reveals its more complicated meaning in comparison with that of conflict. It is rendered by the semantic features, indicating length ('a time'), emotional impact ('danger') and impediments ('difficulty' and 'problem'). The naïve grasp of crisis correlates with its understanding in terms of a rhetorical situation, defined as a complex of persons, events, objects, and relations, presenting an actual or potential exigency (Bitzer 1968: 6). This definition underscores an affinity between the naïve and rhetorical interpretations of crisis considered in terms of cognitive primes for force: on the one hand, difficulties stand for impediments, and on the other, impediments are akin to exigency. This correlation is not accidental since rhetoric is meant to influence masses of people with linguistic means playing an important role in it.

Crisis as a rhetorical phenomenon (Kuypers 1997: 8) has two facets: the first is the presidential crisis rhetoric which can be treated as an instance of crisis communication, i.e. its discussions by the management and journalists (Rzepecka 2018: 8); the second is the media crisis that concerns reporting and categorizing certain events in these particular terms since most people do not experience it themselves but learn of it from the media (Holladay 2010: 161). Crises also differ with respect to causes: they may be brought about by natural disasters (Adkins, 2010: 93), chemical accidents (Holladay 2010: 159) or violent conflicts, triggering the formation of a conflict - crisis news hierarchy. In its turn, conflict news has 
two peculiarities: first, journalists are not reporting the facts, they are telling stories about the conflict; second, they have at least some power over the impact of their reporting on the public (Hoxha, Hanitzsch 2018: 24).

With that in mind, this paper develops a cognitive-rhetorical method for the analysis of the functioning of conflict - crisis units in the news stories about Ukrainian conflict-crisis published on the BBC site (https://www.bbc.com/news). The choice of the source media is explained by two main reasons: on the one hand, the British Broadcasting Corporation is often claimed to offer the best prospect of impartial, high-quality journalism that is insulated from considerations of profit or politics (Freedman 2019: 203), on the other hand, the status of the BBC as a market leader provides a key narrative for subsequent stories published by other news outlets (Hoxha, Hanitzsch 2018: 24), reflecting its powerful role in contemporary media world.

\section{Methods}

Since the media in general and news in particular are increasingly used as means of influencing the audience the paper draws on the cognitive rhetorical methodology meant for studying linguistic devices and strategies employed by the senders of "practical-purpose" messages with the aim of affecting the recipients' viewpoint and way of thinking (Kwiatkowska 2012: 9). The approach is developing in two directions: atomistic, applying separate cognitive procedures to the analysis of messages, and holistic, incorporating cognitive techniques into the traditional tools of rhetoric. They encompass ethos as self-representation; pathos appealing to emotions; and logos influencing thinking; as well as the canons of invention, concerning the choice of arguments; disposition, dealing with their arrangement; elocution as selection of linguistic means; memory and delivery (Burk 2016: 2). Due to the development of modern technologies, enhancing the reach of the human voice, the last two canons have merged forming media discourse investigated by virtual rhetoric (Aczél 2016: 5). The latest cognitive rhetorical study of holistic type combines persuasive appeals with Ronald Langacker's construal theory, mainly based on the principles of visual perception (Browse 2018: 113). However, besides perception, cognitive linguistics takes into account the general cognitive abilities of attention, memory, categorization and abstraction (Dąbrovska, Divijak 2019: 2) which must be incorporated into cognitive rhetorical studies.

One of the ways of abstraction, underlying human thinking and communication, rests on force relations, treated as primes of cognitive activity by two conceptions. Force dynamics evokes the opposition between the Agonist as a focal force and the Antagonist as its opponent with their inner tendencies to motion or rest (Talmy 2000: 409). The experiental theory draws on image schemas, i.e. dynamic recurring patterns of organism-environment interaction (Johnson 2005: 19). Unlike force dynamics with its attention to the internal states of two opposing entities (Talmy 2000: 409), image schemas capture organismenvironment interactions from an observer's perspective. With their inward 
Conflict - crisis hierarchy in English news discourse: Cognitive rhetorical perspective

structure comprising source, vector and target (Johnson 1987: 46), image schemas for force turn out to be more suitable for the cognitive rhetorical reconstruction of the conflict-crisis hierarchy than force dynamics.

The core of the image schemas for force is represented by COUNTERFORCE, rendering the head-on meetings of entities (Johnson 1987: 46) with approximately similar power. As a means of conceptualisation COUNTERFORCE permeates numerous spheres of human activity such as war, combat, argument, dispute, debate (Dancygier, Sweetser 2014: 13) as well as games, battles and controversy, determining news discourse organisation (Cramer 2011), etc. The derivative forces emphasise the dominance of one of the COUNTERFORCE constituents indicating the deterioration of or solution to the problems characterising the naïve comprehension of crisis. DIVERSION is regarded as a change of force following the collision of two vectors (Johnson 1987: 45); BLOCKAGE is treated as encountering a barrier and then taking any number of possible directions (ibid) while RESTRAINT REMOVAL suggests an open way or path making an exertion of force possible (ibid). The COMPULSION schema captures the experience of being moved by external forces while ATTRACTION underlies drawing or pulling the target (ibid). The ENABLEMENT / DISABLEMENT schemas render a sense of power or its lack (ibid) respectively.

The rhetorical impact of conflict - crisis hierarchy defined in terms of cognitive force primes rests on the textual visibility of naming units due to their position on the intersection of vertical and linear layout of a news item. The vertical prominence results from the use of the units under discussion in headings, meant to attract the recipient's attention to a long-lasting mega-event; headlines, focusing the reader's attention on the mega-event instances; text bodies, sustaining his / her attention. Accordingly, the primary degree of prominence is associated with the terms unrest, conflict or crisis denoting confrontation in the headings. The intermediary level of salience is achieved by the units protests, standoff, war focusing the reader's attention in headlines on the COUNTERFORCE types and components. The final level of prominence includes the units denoting particular COUNTERFORCE instances: clash, defy, throw, storm. The linear salience of the units under discussion results from their foregrounded or backgrounded position in separate paragraphs making up the sections following the headline: Lead, Main event, Previous event, Context, Background (Dijk 1985: 75). The news stories under consideration vary in size occupying one or two print pages though the analysis undertaken concerns those sections and paragraphs which hinge on the evolvement of conflict - crisis hierarchy.

In the vertical hierarchy, the noun conflict turns out to have a balanced meaning since the semantic features 'disagreement' and 'argument' indicate that it represents COUNTERFORCE constituents with a similar power in a natural order of perception, i.e. from source to target. Consequently, conflict-headings subordinate headlines representing opposing praticipants from a distant perspective in case of shelling, e.g. Ukraine conflict: Shelling rages on after nightfall (03 Feb. 2017), or naming the source and target represented in the 
following example by bombs and a settlement respectively, e.g. Ukraine conflict: Jet bombs rebel-held town of Snizhne (15 Jul 2014).

Unlike the term conflict occupying the initial place in the rhetorical ethos pathos opposition, other units intensify the role of COUNTERFORCE components emphasising pathos features. The intermediary position between ethos and pathos belongs to the noun unrest focusing on the COUNTERFORCE source indicated by the semantic feature 'people protest' in the definition of the word as "a political situation in which people protest or behave violently" (LDOCE). This feature of initiative is encoded in the news by combining this term with the nouns denoting social actors, e.g. People engaged in the unrest had distinct Russian accents (https://www.bbc.com/news/world-europe-26919928); their supporters, characterised by the verbs create, foment, provoke, cause, stir, e.g. Moscow denied allegations that Russian agents had been fomenting unrest in east Ukraine (https://www.bbc.com/news/world-europe-27018199); the length of this stage, e.g. Ukraine's unrest began in November, when President Yanukovych rejected a trade deal with the EU (https://www.bbc.com/news/world-europe26249330).

The noun crisis associates the pathos effect with emotions rendered by the semantic feature 'danger' in combination with different kinds of BLOCKAGE enhancing the role of the COUNTERFORCE source: physical, indicated by the semantic feature 'difficulty'; perceptual, singled out by the feature 'confusion', which, in its turn, is defined as "not understanding what is happening or what something means because it is not clear" (LDOCE). However, news texts offer a richer picture of crisis representation than the discussed definition: this term combines with an array of other units evoking cognitive structures contributing to the emphatic reconstruction of crisis: they denote its extent, e.g. Mr Kerry said the extent of the crisis had been highlighted in recent days (https://www.bbc.com/news/world-europe-27072351); represent it as a container enveloping a country, e.g. Ukraine has been in crisis since President Yanukovych was toppled in February (https://www.bbc.com/news/world-europe-27083395); depict it as a sequel of previous events, e.g. Russia's move into Crimea triggered a diplomatic crisis (https://www.bbc.com/news/world-europe-26725659), etc.

The second level of the conflict - crisis hierarchy includes two most frequent units occurring in the headlines and text bodies to trigger tension and might effects respectively: stand-off and war. The tension effect, evoked by the word stand-off, arises from the inability of either source or target to get an upper hand. It is indicated by the semantic feature 'neither side' in the definition of stand-off as "a situation in which neither side in a fight or battle can gain an advantage" (LDOCE). In the news, this effect is emphasised by attributes tense, intensifying, violent, e.g. Ukraine protesters in tense stand-off in central Kiev (https://www.bbc.com/news/world-europe-25298481). The challenge is the use of the noun war. Though the semantic analysis indicates its relation to a mighty kind of COUNTERFORCE texts seem to mitigate this meaning since it is used in the following positions. First, the noun war occurs in the quotes of Ukrainian politicians trying to aggravate the representation of the current state of affairs, e.g. Ukraine's interim government has accused Russia of having declared war, and 
Conflict - crisis hierarchy in English news discourse: Cognitive rhetorical perspective

has ordered the mobilization of its armed forces (03.03.2014), or to refer to the holy war archetype in combination with the unit fight in the headline The Russians fighting a holy war in Ukraine (18.12.2014). Secondly, the noun war escalates the representation of consequences: it is used to foretell the possible developments, e.g. Ex-president warns Ukraine 'on brink of civil war' (29.01.2014), or in interaction with the noun battle it predicts possible results of the COUNTERFORCE enactment between the neighboring states, e.g. If this turns into a full-scale battle of wills between Moscow and Kiev, the consequences could be unthinkable - at worst the provocation of a bitter civil war inside Ukraine (1.03.2014).

However, at a later date, namely on 11 July 2016, an analytical BBC publication treats the COUNTERFORCE in the east of Ukraine as a full-fledged war though the noun conflict is also used here to refer to the same situation:

When the war broke out in the east of Ukraine in the spring of 2014, Canadian NGOs rallied to provide winter boots and uniforms for a skeletal Ukrainian military, which had suffered years of post-Soviet neglect

But perhaps the most vivid example of Canadian help can be seen through the Ukrainian men who have been irreparably scarred, both physically and mentally, by the conflict. (https://www.bbc.com/news/world-europe-36739074)

It turns out that in the context of crisis the noun war performs in the news two rhetorical functions: on the one hand, it is related to ethos when it refers to the mighty COUNTERFORCE predicting dire consequences, on the other hand, it evokes pathos features being used to refer to a full-fledged confrontation between mighty participants.

The final level of conflict - crisis hierarchy includes the units clash, defy, throw, storm etc. denoting particular COUNTERFORCE instances in the text body with a sporadic occurance in headlines. In interaction with the units of the two upper levels they form three rhetorical patterns to be discussed below: zoomin, zoom-out, perspectivational.

\section{Results and Discussion}

The application of the cognitive rhetorical methodology based on the combination of image schemas for force with the three-tiered attention structure of news texts yields the following results of studying the conflict - crisis construction at the levels of headings, attracting the recipient's attention to mega-events; headlines, focusing it on their instances; text bodies, sustaining it.

\subsection{Zoom-in patterns of conflict - crisis construction in news texts}

The zoom-in construction of conflict - crisis hierarchy, resting on an increase in attention to detail, has two types: regular, involving an interaction of the terms referring to COUNTERFORCE at different levels of the hierarchy; and 
argumentative, supplemented with the sections of evidence, explanation or comments.

The regular zoom-in pattern is implemented by the opposition of the terms with general and specific meanings in the successive sections of a news story. This pattern rests on the interaction of the general terms unrest, conflict, crisis in the headings with the units clashes, defy, throw, storm etc referring to physical COUNTERFORCE throughout the text.

With respect to the distance between the words in the hierarchy there are patterns with minor, significant, and metaphoric degrees of zoom-in.

The minor degree of zoom-in is rendered by the units in close relations in the hierarchy which is exemplified by the textual interaction of the words face-off (clash, discussion) - inflict with the term unrest referring in the heading to a COUNTERFORCE source and correlating in the text body with the units denoting physical and communicative COUNTERFORCE:

(1) Ukraine unrest: (2) Rival politicians face off at summit.

(3) Ukraine's Foreign Minister Leonid Kozhara and opposition leader Vitali Klitschko have clashed face to face at a security summit in Munich.

(4) The two men appeared in a discussion, during which Mr Klitschko showed Mr Kozhara images of injuries he said were inflicted by the police on protesters. (https://www.bbc.com/news/world-europe-26004585)

The piece above differentiates two kinds of COUNTERFORCE. In the heading (1), the noun unrest focuses on protesters as a COUNTERFORCE source while the verb inflict in the text body (4) refers to physical COUNTERFORCE between the police and the protesters that, in its turn, serves as a subject of argument for two Ukrainian politicians. They are assigned the roles of communicative COUNTERFORCE source and target by the phrasal verb face off in the headline (2), the verb clash in the lead (3) and the noun discussion in the text body (4).

The significant degree of regular zoom-in is brought about by the distant semantic relations in the meaning of the units within the hierarchy, for example, crisis and clashes:

(1) Ukraine crisis: (2) Clashes after thousands defy protest ban.

(3) Clashes have taken place after large crowds of pro-EU demonstrators rallied in Ukraine's capital Kiev against new laws restricting public protests.

(4) Stun grenades and flares were thrown as protesters tried to reach parliament, their way blocked by police and buses. (https://www.bbc.com/news/world-europe-25798320)

The cited item suggests that the term crisis in the heading (1) is meant to attract the addressee's attention to several instances of physical COUNTERFORCE and its transforms in the text. They are denoted by the noun clashes, which usually refers to a short fight between two armies or groups (LDOCE), the construction thousands defy in the headline (2), and the noun clashes returning the reader in the lead (3) to a recent COUNTERFORCE outlined in the headline. Against this background, the text body (4) specifies the protesters as a source of physical 
Conflict - crisis hierarchy in English news discourse: Cognitive rhetorical perspective

COUNTERFORCE referring to their use of stun grenades and flares with police acting as a source of BLOCKAGE (their way blocked by police and buses).

The metaphoric zoom-in is represented by crisis - war of words opposition with the latter referring in the text body (2) to communicative COUNTERFORCE which is also denoted by the noun accusation in (2), while the physical COUNTERFORCE is evoked by the construction plotted a sabotage attack in the same utterance:

(1) Crimea crisis: Ukraine-Russia tensions spill on to the beach [...].

(2) The war of words between Russia and Ukraine has intensified following Moscow's accusation that Kiev plotted a sabotage attack in Crimea. (https://www.bbc.com/news/worldeurope-37093419)

The zoom-in argumentative patterns extend the depicted COUNTERFORCE by sections of evidence, explanation or comments.

The evidence section is added to zoom-in texts to support the idea of crisis, indicated in the heading, by reference to physical COUNTERFORCE proving that the event really took place. Attracting the addressee's attention in the heading of the text below to an array of events the term crisis correlates in the headline (2) with the units sanctions referring to BLOCKAGE and bloodshed related to DISABLEMENT as well as with the nouns sanctions, violence and unrest in the lead (3) representing the state of affaires from different perspectives:

(1) Ukraine crisis: (2) EU sanctions push over Kiev bloodshed.

(3) Europe's leaders are to consider urgent sanctions against Ukraine after the worst violence in months of unrest claimed at least 26 lives.

(4) There were sporadic clashes on Wednesday following Tuesday night's police bid to dislodge protesters from their stronghold in the capital Kiev. (https://www.bbc.com/news/world-europe26258998)

The evidence for physical COUNTERFORCE is introduced by the noun clashes at the beginning of the text body (4) to prove that the causes for the promised sanctions hold.

The explanation section extends the zoom-in patterns, referring to the causes of the COUNTERFORCE by units belonging to different levels of the hierarchy, that is exemplified by the text below:

(1) Ukraine crisis: (2) Blast injures Luhansk rebel leader Plotnitsky.

(3) The Luhansk People's Republic and the larger Donetsk People's Republic were proclaimed by the separatists shortly after conflict broke out in eastern Ukraine in 2014.

(4) The clashes in the east began shortly after Russia annexed Ukraine's southern Crimea peninsula. (https://www.bbc.com/news/world-europe-37000601)

In the cited news item, the zoom-in steps are named by the term crisis in the heading (1) and the noun blast referring to the source of physical COUNTERFORCE in the headline (2). In the explanatory sections, the units conflict in (3) and clashes in (4) elucidate the COUNTERFORCE at two levels: local (shortly after conflict broke out in eastern Ukraine in 2014) and national 
(The clashes in the east began shortly after Russia annexed Ukraine's southern Crimea peninsula).

Comments sections usually quote officials assessing the state of affairs after its zoom-in representation. In the text below, the zoom-in pattern rests on the crisis - physical COUNTERFORCE opposition:

(1) Ukraine crisis: (2) Police storm main Kiev 'Maidan' protest camp.

(3) Explosions are taking place, fireworks are being thrown and large fires have broken out in Independence Square.

(4) On Tuesday at least 18 people were killed, including seven policemen, in the worst violence seen in weeks.

(5) President Viktor Yanukovych blamed the violence on opposition leaders, but said it was still

"not too late to stop the conflict". (https://www.bbc.com/news/world-europe-26249330)

The term crisis from the heading (1) of the cited text correlates with the verbs intensifying the representation of physical COUNTERFORCE and its transforms: storm with a metaphorical meaning in the headline (2); throw in the lead (3), and kill denoting in the text body (4) a deadly outcome associated with DISABLEMENT. Against this bellicose backdrop, the noun conflict, referring to a balanced COUNTERFORCE in (5), offers the president's view of the current state in the country though it seems to contradict the critical multitude of forces evoked in the text.

Similarly, an additional comment section supports the zoom-in pattern implemented by the units crisis - negotiations - unrest in the text below:

(1) Ukraine crisis: (2) Peaceful negotiations 'futile'.

(3) Efforts to resolve Ukraine's unrest in the capital Kiev by peaceful means are "futile".

(4) Minister Vitaliy Zakharchenko said negotiations with the protesters had failed.

(5) He blamed "radical groups" for the unrest, adding protesters had arms. (https://www.bbc.com/news/world-europe-25894296)

The crisis-heading (1) establishes an editorial view of the situation with the unit negotiations in the headline (2) and the text body (4) referring to the communicative COUNTERFORCE between the government and the protesters. Meanwhile the noun unrest in the lead (3) and in the body (5) implies that the minister's accusations are leveled against the protesters, perceived as a source of physical COUNTERFORCE.

To sum up, the zoom-in pattern underlying a detailed COUNTERFORCE description in the news has two variants: regular with no supporting sections and argumentative when the COUNTERFORCE portrayed in the text body requires additional evidence, explanation or comments. The argumentative sections of news texts are generally introduced by the primary-level terms to draw the reader's attention.

\subsection{Zoom-out patterns of conflict - crisis construction in news texts}

The zoom-out patterns shift the addressee's attention from the COUNTERFORCE details indicated in the beginning of a text to its general portrayal usually 
Conflict - crisis hierarchy in English news discourse: Cognitive rhetorical perspective

accompanied by additional emphasis on vertical or horizontal foregrounding / backgrounding of the units.

The unrest - crisis zoom-out opposition is implemented by foregrounding the noun unrest in the heading and backgrounding the unit crisis representing a target of RESTRAINT REMOVAL in the text body:

(1) Ukraine unrest: (2) Protesters storm regional offices.

(3) Anti-government demonstrators in Ukraine are expanding their protests after talks between the opposition and President Viktor Yanukovych stalled.

(4) In western Ukraine, activists seized the regional government office in the city of Ivano-

Frankivsk and are storming another one in Chernivtsi.

(5) Protests were reported in Lutsk, in the north-west, and Sumy, in the east.

(6) Meanwhile, Mr Yanukovych vowed to use "all legal means" if a solution to the crisis is not found. (https://www.bbc.com/news/world-europe-25876807)

At first glance, the terms unrest and crisis in the cited text seem to refer to the same state of affairs though with a difference. The meaning of the noun unrest in the heading (1) correlates in the text with four foregrounded units: protesters in the headline (2), anti-government demonstrators in (3), activists in (4) and protests in (5). They refer to the COUNTERFORCE source located in a number of territories denoted by the accompanying adverbial modifiers. Consequently, it is not surprising that the situation in general is named by the term crisis in (6) with the noun solution representing this state of affairs as a target of RESTRAINT REMOVAL. Moreover, the discourse marker meanwhile in (6) indicates that the crisis solution is not the main topic of the news story.

In analytical texts, the zoom-out pattern with the second war-element mainly serves as a means of rumination on the outcome of the COUNTERFORCE portrayed in the text: the two consecutive oppositions gamble-crisis and conflict - war in the extract below metaphorically depict the COUNTERFORCE evolvement in two countries with a similar destiny:

(1) Moscow's Ukraine gamble.

(2) This is fast turning into the worst crisis between Russia and the West since the short conflict between Georgia and Russia back in 2008.

(3) That war ended with Georgia humbled and the Russians firmly in control of two breakaway, largely Russian-speaking Georgian enclave. (https://www.bbc.com/news/world-europe26403297)

The excerpt above rests on two zoom-out sets of units: in the first one the noun gamble from the headline (1) correlates with the term crisis in the lead (2) generalising the COUNTERFORCE representation of events in Ukraine while the second pair, comprising conflict in the lead (2) and war in the text body (3), emphasises on an increase in COUNTERFORCE intensity in Georgia ten years before. 
To sum up, the zoom-out COUNTERFORCE patterns reveal different points of view on the same state of affairs which is more characteristic of analytical articles reflecting on the depicted situation.

\subsection{Multiperspectivational patterns of conflict - crisis construction in news texts}

The multiperspectivational patterns denote components of COUNTERFORCE or its transforms by different units in the heading, headline and text body to provide an impression of balanced reporting. With respect to the number of referents highlighted this pattern is subdivided into dual and triple while with regard to the position of the referring terms it may be sandwiched.

The dual subpattern rests on two terms shifting the reader's attention from one component of COUNTERFORCE to the other. The unrest - stand-off opposition in the text below switches the addressee's attention from the protesters as COUNTERFORCE source to the responsibility of both sides:

(1) Ukraine frees all the protesters detained during unrest.

(2) Ukrainian authorities have freed the last of 243 protesters detained during almost three months of unrest, the opposition have confirmed.

(3) The detainees were released under an amnesty passed last month to defuse an increasingly violent stand-off. (https://www.bbc.com/news/world-europe-26187299)

The term unrest in the headline (1) and in the lead (2) portrays COUNTERFORCE from the protesters' perspective with the adverbial modifier during almost three months in the lead (2) emphasising its length. However, the noun stand-off in the text body (3) refers to both COUNTERFORCE sides underlining the ensuing tension by the attribute increasingly violent.

The triple subpattern is rendered by three terms from the hierarchy under discussion, for example, crisis - unrest - stand-off. In this case, the overall state of affairs is depicted by the term crisis in the heading, the protesters' perspective is set by the unit unrest and both sides' responsibility is designated by the noun stand-off:

(1) Ukraine crisis: Leaked phone call embarrasses US.

(2) An apparently bugged phone conversation in which a senior US diplomat disparages the EU over the Ukraine crisis has been posted online.

(3) The EU and US are involved in talks to end months of unrest in Ukraine.

(4) At one point, the female speaker mentions the UN and its possible role in trying to find a solution to the Ukraine stand-off. (https://www.bbc.com/news/world-europe-26072281)

The noun crisis in the heading (1) of the cited text draws the addressee's attention to the piece of news implying an interaction of multiple forces while its repetition in the lead (2) supports the dominance of the suggested viewpoint. The other two units in the background positions of the text body refer to the same state of affairs from differing perspectives: the noun unrest in (3) indicates the view of the reporter siding with the protesters while the noun stand-off in (4) renders a 
Conflict - crisis hierarchy in English news discourse: Cognitive rhetorical perspective

personal opinion of an American female speaker focusing on the responsibility of both sides engaged in the COUNTERFORCE.

The sandwiched pattern involves the textual representation of COUNTERFORCE at a general level with separate zooms-in in between. In the text below, the term crisis implies the interaction of a multitude of forces indicated in the heading (1), the lead (2) and the text body (4) with an intermediary emphasis on the source of physical COUNTERFORCE indicated by the noun unrest in (3):

(1) Ukraine crisis: Yanukovych ready to resume EU talks.

(2) Mr Yanukovych discussed the crisis at a televised round table on Tuesday.

(3) The unrest in Kiev and other parts of Ukraine escalated after police used violence against protesters.

(4) The crisis has highlighted divisions in Ukraine, with many in the east of the country more sympathetic to Russia. (https://www.bbc.com/news/world-europe-25311018)

To sum up, out of the three textual patterns underlying conflict - crisis construction in the news - zoom-in, zoom-out and multiperspectivation - the most frequent is the zoom-in with a detailed account of COUNTERFORCE, its components and transforms, accompanied by the argumentational sections of evidence, explanation or comments. The second frequent pattern is that of zoomout, generalizing the state of affairs. The multiperspectivational pattern involves depicting COUNTERFORCE from different points of view to create an impression of balanced reporting. According to these patterns, the noun crisis has a tendency to be foregrounded to attract the addressee's attention to the multiple forces involved in the mega-event while other terms from the hierarchy render different points of view, emphasising particular COUNTERFORCE components or types.

\section{Conclusions}

The analysis shows that three units - unrest, conflict and crisis - form the primary level of confrontation hierarchy rendering COUNTERFORCE complication due to the dominance of the source, its balance with the target or interaction of the multitude of forces respectively. The intermediary level of the hierarchy includes the terms employed in headlines to focus the reader's attention on the evolvement of conflict into crisis: they comprise the units protests, standoff, storm, war. The final level incorporates the words clashes, defy, throw drifting between the headline and the text body to denote different kinds of COUNTERFORCE or its transforms. The textual arrangement of units under discussion is subordinated to three patterns: zoom-in, offering a detailed portrayal of events supported by the sections of evidence, explanation or comments introduced mainly by the primary level terms; zoom-out, generalizing the presentation of COUNTERFORCE and its transforms; multiperspectivation, providing for balanced reporting. 


\section{References}

Adkins, Gabriel L. 2010. Organizational Networks in Disaster Response: An Examination of the US Government Network's Efforts in Hurricane Katrina. In: W. Timothy Coombs and Sherry J. Holladay (eds.), The Handbook of Crisis Communication, 93-114. Oxford: Wiley-Blackwell. https://doi.org/10.1002/9781444314885.ch4

Aczél, Petra. 2016. Virtual rhetoric. A theoretical approach. Res Rhetorica, 3(4), 1-15. Available from: https://resrhetorica.com/index.php/RR/article/view/168. [Accessed: $18^{\text {th }}$ September 2020]

Bitzer, Lloyd. 1968. The Rhetorical Situation. Philosophy and Rhetoric, 1, 1-14.

Bray, Peter and Marta Rzepecka. 2018. Introduction. Communication and conflict. In P. Bray and M. Rzepecka (eds.), Communication and Conflict in Multiple Settings, 1-12. Leiden: Brill. https://doi.org/10.1163/9789004373679

Browse, Sam. 2018. Cognitive Rhetoric: The Cognitive Poetics of Political Discourse. Amsterdam (Phil.): John Benjamins. https://doi.org/10.1075/lal.31

Burke, Michael. 2016. Discourse implicature, Quintilian and the Lucidity Principle: rhetorical phenomena in pragmatics. Topics in Linguistics, 17(1), 1-16. Available from: https://content.sciendo.com/view/journals/topling/17/1/article-p1.xml [Accessed: $18^{\text {th }}$ September 2020] https://doi.org/10.1515/topling-2016-0001

Coombs, W. Timothy. 2010. Parameters for crisis communication. In W. T. Coombs and S. J. Holladay (eds.), The Handbook of Crisis Communication, 17-53. Oxford: Wiley-Blackwell.

Cramer, Peter A. 2011. Controversy as News Discourse. Dordrecht, Heidelberg, London, New York: Springer Science + Business Media.

Croucher, Stephen M. 2017. Changes in conflict over time. A longitudinal examination of conflictstyle approaches. In B. Lewandowska-Tomaszczyk, P. A. Wilson, S. M. Croucher (eds.), Approaches to Conflict: Theoretical, Interpersonal, and Discursive Dynamics, 33-42. Lanham: Lexington Books.

Dąbrovska, Ewa and Dagmar Divijak. 2019. Introduction. In E. Dąborvska and D. Divijak (ed.), Cognitive Linguistics Foundations of Language, 1-10. Berlin / Boston: Walter de Gruyter.

Dancygier, Barbara and Eve Sweetser. 2014. Figurative Language. Cambridge: Cambridge University Press.

Demmers, Jolle. 2012. Theories of Violent Conflict: An Introduction. London, New York: Routledge. https://doi.org/10.4324/9780203869512

Dijk, Teun van. 1985. Structures of News in the Press. In Teun Dijk van (ed.), Discourse and Communication, 69-93. Berlin: De Gruyter.

Freedman, Des. 2019. "Public service" and the journalism crisis: Is the BBC the answer? Television and News Media, 20 (3), 203-218. https://doi.org/10.1177/1527476418760985

Heath, Robert. 2010. Introduction. In W. T. Coombs and S. J. Holladay (eds.), The Handbook of Crisis Communication, 1-13. Oxford: Wiley-Blackwell.

Holladay, Sherry. 2010. Are They Practicing What We Are Preaching? An Investigation of Crisis Communication Strategies in the Media Coverage of Chemical Accidents. In W. T. Coombs and S. J. Holladay (eds.), The Handbook of Crisis Communication, 159-180. Oxford: WileyBlackwell. https://doi.org/10.1002/9781444314885.ch7

Hoxha, Abit and Thomas Hanitzsch. 2018. How conflict news comes into being: Reconstructing reality through telling stories. Media, War \& Conflict, 11(1), 22-45. https://doi.org/10.1177/1750635217727313

Johnson, Mark. 1987. The Body in the Mind: The Bodily Basis of Meaning, Imagination, and Reason. Chicago, London: The University of Chicago Press.

Johnson, Mark. 2005. The philosophical significance of image schemas. In B. Hampe (ed.), From Perception to Meaning. Image Schemas in Cognitive Linguistics, 15-33. Berlin, New York: Mouton de Gruyter. https://doi.org/10.7208/chicago/9780226177847.001.0001

Knoblock, Natalia. 2020. Introduction. In N. Knoblock (ed.), Language of Conflict: Discourses of Ukrainian Crisis, 1-15. New York: Bloomsbury Academic. https://doi.org/10.5040/9781350098633.0005

Kuypers, Jim. 1997. Presidential Crisis Rhetoric and the Press in the Post-Cold War World. Westport: Praeger Publishers. 
Conflict - crisis hierarchy in English news discourse: Cognitive rhetorical perspective

Kwiatkowska, Alina. 2012. From the editor. In A.Kwiatkowska (ed.), Texts and Minds: Papers in Cognitive Poetics and Rhetoric, 7-10. Frankfurt am Main: Peter Lang. https://doi.org/10.3726/978-3-653-04564-2

Makhotykh, Mykola and Maryna Sydorova. 2017. Social media \& visual framing of the conflict in eastern Ukraine. Media, War \& Conflict, $10 \quad$ (3), 359-381. https://doi.org/10.1177/1750635217702539

LDOCE: Longman Dictionary of Contemporary English. Available from: https://www.ldoceonline.com/ [Accessed: 18th September 2020]

OALD: Oxford Advanced Learner's Dictionary. Available from: https://www.oxfordlearnersdictionaries.com/ [Accessed: 18th September 2020]

Ojala, Marcus and Mervi Pantti. 2017. Naturalising the new cold war: The geopolitics of framing the Ukrainian conflict in four European newspapers. Global Media and Communication, 13, 4156. https://doi.org/10.1177/1742766517694472

Pasitselska, Olga. 2017. Ukrainian crisis through the lens of Russian media: Construction of ideological discourse. Discourse and Communication, 11, 591-609. https://doi.org/10.1177/1750481317714127

Rzepecka, Marta. 2018. Analyzing President Obama's crisis rhetoric: The case of Syria. Tekst $i$ Dyskurs, 11, 405-425. Available from: http://cejsh.icm.edu.pl/cejsh/element/bwmeta1.element.desklight-b901e794-d90f-4558-8e26e553e9951b51 [Accessed: 18th September 2020]

Schnabel, Albrecht and David Carment. 2004. Mainstreaming conflict prevention: From Rhetoric to reality. In S. Albrecht and D. Carment (eds.), Conflict Prevention: From Rhetoric to Reality, vol. 1, 3-21. Lanbam: Lexington Books.

Talmy, Leonard. 2000. Force dynamics in language and cognition. In L. Talmy (ed.) Concept Structuring Systems, vol. 1, 409-470. Cambridge (Mass): The MIT Press.

Watanabe, Kohei. 2017. Measuring news bias: Russia's official news agency ITAR-TASS' coverage of the Ukraine crisis. European Journal of Communication, 32, 224-241. https://doi.org/10.1177/0267323117695735 